\title{
Nanogram per Kilogram per Minute
}

National Cancer Institute

\section{Source}

National Cancer Institute. Nanogram per Kilogram per Minute. NCI Thesaurus. Code C85743.

Nanograms per kilogram per minute. 